\title{
An Experimental Investigation and Numerical Simulation in SPF of AA 5083 Alloy using Programming Logic Control Approach
}

\author{
Muthusamy Balasubramanian $1,{ }^{*}$ - Pasupathy Ganesh ${ }^{2}-$ Kalimuthu Ramanathan ${ }^{3}$ \\ - Velukkudi Santhanam Senthil Kumar ${ }^{4}$ \\ ${ }^{1}$ Anna University, University College of Engineering, India \\ ${ }^{2}$ Anna University, Madras Institute of Technology, India \\ ${ }^{3}$ Alagappa Chettiar College of Engineering and Technology, India \\ ${ }_{4}^{4}$ Anna University, College of Engineering Guindy, India
}

A new programming logic control method is proposed to predict the pressure during the superplastic forming process with improved forming characteristics of AA 5083 alloy sheets. The method has produced a better uniformity thickness profile in a complex, multidimensional profile in comparison with existing methods. To optimize pressure during the forming process, it is possible to maintain an optimum strain rate. Accurate control of the magnitude and duration of forming pressure and, as a result, the achievement of uniform thickness distribution in the taper angle, die corner, entry regions, and micro-forming of the multidimensional dome has been proved in this paper. Profiles formed without significant wrinkles and necking have been obtained via the fine adjustment of the applied pressure. The experimentally obtained results, using a multidimensional dome profile, are compared with the finite element method (FEM) simulated results and both are found to be in good agreement. The influence of key factors such as strain rate sensitivity index and friction coefficient on the optimum pressure-time cycle and also on the thickness distribution of the profile have been investigated and optimized. Furthermore, the microstructure was examined in parent metal and superplastically formed components.

Keywords: superplastic forming, finite element method, programming logic control circuit, aluminium 5083 alloy, multidimensional dome

Highlights

- A multistage multidimensional profile has been performed with a single blow forming operation.

- Optimum pressure time cycle was predicted to obtain uniform thickness distribution by using a newly proposed programming logic control method.

- Finite element modelling results were found to be fairly in agreement with the experimental results.

- Minimum forming time, forming pressure and uniform thickness profile obtained as a function of friction coefficient and strain rate sensitivity index.

- Obtained uniform thickness profile with a function of die entry radius, taper angle, die corner, and micro-forming regions.

\section{INTRODUCTION}

Superplastic forming is an important technique that can be found in the aerospace industry, automobile exterior components and turbine blades, where various dimensions have to be created in a single blowforming operation. In such situations, prior knowledge of multidimensional profile forming operations will be highly relevant and useful. Factors including uniform thickness distribution, prevention of excessive thinning and wrinkles in the final product assume paramount importance in any multidimensional superplastic forming process. For achieving uniform thickness distribution in a multidimensional profile, controlling pressure during the blow forming process is essential. In order to control the forming pressure, the strain rate needs to be maintained at an optimum value. Previously, different numerical methods were used for the prediction of optimal pressure cycle in a long rectangular box [1], circular cup [2], hemispherical dome [3], and cone cup of simple shape components [4]; these consumed more time for computation and experimentation; furthermore, material elongation with a genetic approach [5] consumes more time for computation and mutation. To make both theoretical prediction and experimentation faster, sophisticated modeling and simulation approaches have been used recently for studying superplastic forming behaviour.

Dutta and Mukherjee [6] have developed a simple pressure-time equation for superplastic forming under biaxial stress conditions to predict the required gas pressure to optimize the flow stress, strain rate and geometric properties of the sheet thus formed. Using the ABAQUS code, Jarraret et al. [7] have analysed high-temperature bulge forming of $5083 \mathrm{Al}$ alloy by keeping the pressure constant but at different 
levels and reported the ability of the model to predict deformation behaviour. Balasubramanian et al. [8] have optimized the uniform thickness distribution in different die radii domes (the parametric design models) and different die entry regions in a three-stage hemispherical dome with constant pressure method. Carrino et al. [9] have proposed a time incrementalloading process to maintain maximum strain rate during the pressure cycle. They have reported a decrease in forming time, better material flow, and uniform thickness distribution in a circular cup. Snippe and Meinders [10] have suggested the backpressure method for obtaining maximum dome height in a spherical vessel and proposed improvements in leak tightness. Dezelak et al. [11] have analysed the effect of the twist spring back method for a metal sheet by using elastic-plastic shell elements in a finite element method (FEM) simulation. Hambli et al. [12] have used a constrain algorithm to predict the pressure cycle in 2D and 3D finite element analysis (FEA) models and found no significant difference between the results obtained from 2D and 3D FEA simulations of a simple conical cup.

Nituet et al. [13] have reported that a finite element simulation process was used to predict the forming characteristics with minimum forming time with high precision. Luckey et al. [14] have developed a pressure prediction algorithm under the average scheme method to maintain a target strain rate and reported that the scheme improves the thickness profile in single-stage rectangular components. Aoura et al. [15] have proposed the constant stress control method to predict the pressure cycle for superplastic forming processes. They have suggested this method to be a better one to maintain the optimum strain rate and to obtain a uniform distribution of thickness in axi-symmetric components. Jarrar et al. [16] have developed a constrained pressure prediction algorithm to predict optimum pressure, maintaining the maximum strain rate, and to obtain better thinning at different die entry regions of a mid-section of a rectangular pan. Based on a logarithmic pressure control algorithm to predict the pressure cycle and to maintain the maximum strain rate, Hojjati et al. [17] reported that forming time decreases with better thickness distribution in a conical cup when compared to the results obtained using the constant pressure control and constraint control algorithm methods. In these studies, the authors have focused on thickness distribution and minimum forming time, using components with simple shapes.

In this work, a programming logic control (PLC) system has been developed that can control the forming pressure accurately to maintain the strain rate as constant and closer to the optimum value throughout the blow forming process. Furthermore, the coding system also incorporates features that can improve the uniformity of the thickness profile in the taper angle, die entry, die corner and micro-forming regions of multidimensional components. The proposed PLC approach can be designed to change the amplitude of displacement and the time increment even while the forming process is underway, with the provision of interchanging the mode independently. This approach can also be more flexible in allowing sufficient time required for slow filling in corner regions, thereby eliminating the defects caused by otherwise fast filling. Using this coding system in this work, the effect of forming pressure, forming time, and uniformity of thickness with respect to the coefficient of friction, strain rate sensitivity index, and forming temperature have been investigated using a multidimensional dome.

\section{EXPERIMENTAL PROCEDURE}

Experimental validation of the proposed PLC approach for predicting the pressure cycle in superplastic forming (SPF) of an aluminium alloy, AA5083, is presented in this section. From the uniaxial hot tensile tests [8], the optimum forming temperature of AA 5083 was found to be $450{ }^{\circ} \mathrm{C}$ at a strain rate of $1.21 \times 10^{-3} \mathrm{~s}^{-1}$ with the strain rate sensitivity index $\mathrm{m}$ of 0.39 and material constant, $k$, of $159.5 \mathrm{MPa} \mathrm{s}^{-\mathrm{m}}$. The chemical composition and mechanical properties of AA 5083 are given in Tables 1 and 2.

Table 1. Chemical composition of AA 5083 alloy (\% weight)

\begin{tabular}{ccccccccc}
\hline $\mathrm{Si}$ & $\mathrm{Fe}$ & $\mathrm{Cu}$ & $\mathrm{Mn}$ & $\mathrm{Mg}$ & $\mathrm{Cr}$ & $\mathrm{Zn}$ & $\mathrm{Ti}$ & $\mathrm{Al}$ \\
\hline 0.128 & 0.185 & 0.001 & 0.171 & 2.96 & 0.052 & 0.051 & 0.023 & Balance \\
\hline
\end{tabular}

Table 2. Mechanical properties of AA 5083 alloy

\begin{tabular}{lc}
\hline Tensile yield strength [MPa] & 250 \\
\hline Ultimate tensile strength [MPa] & 320 \\
\hline Shear strength [MPa] & 185 \\
\hline Modulus of elasticity [GPa] & 75 \\
\hline Shear modulus [GPa] & 26.4 \\
\hline Poisson's ratio & 0.3 \\
\hline Density $\left[\mathrm{kg} / \mathrm{m}^{3}\right]$ & 2650 \\
\hline Melting point $\left[{ }^{\circ} \mathrm{C}\right]$ & $590-610$ \\
\hline Thermal conductivity $\left[\mathrm{W} \mathrm{m}^{-1} \mathrm{~K}^{-1}\right]$ & 121 \\
\hline
\end{tabular}

The SPF of the PLC process is shown in Fig. 1a and $b$. The air pressure flows into the switched adaptive control system and then is delivered to the 
die cavity with constant or varying pressure. The system can automatically adjust and switch operating parameters according to changes of increment depending upon the forming height and temperature is maintained in the die cavity. Shown in Fig. 1a, the system mainly consists of a PLC control body and switched adaptive control body. The PLC control body includes the central processing unit (CPU) and pressure sensor.

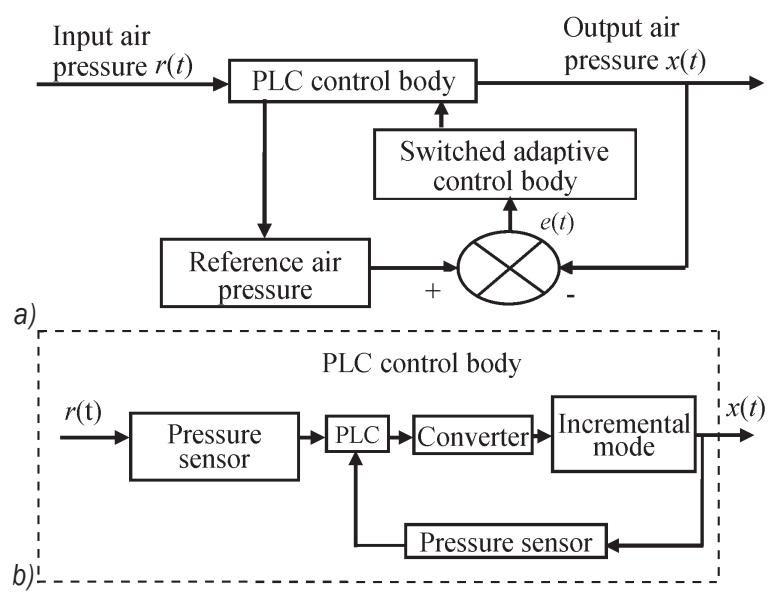

Fig. 1. Block diagram a) of system; b) of PLC control body

The PLC is the core controller of the system. It sets reference air pressure through its internal programs. The reference pressure is compared with real-time ones monitored by pressure transmitter to obtain the deviation. Then, based on the deviation and switched adaptive control algorithm, the PLC gives appropriate instructions to the converter. The pressure transmitter embedded analogue/digital $(\mathrm{a} / \mathrm{d})$ inverter can communicate directly with PLC via recommended standard. All the components constitute a stable closed-loop control system. The PLC control body block diagram as shown in Fig.1b,where the pressure incrementation is performed with programmed pressure profile.

The experimental setup for the SPF process with the PLC processing circuit is shown in Fig. 2. The setup consists of three major parts: the PLC processing circuit, the forming die, and the pressure regulator. In this experimental setup, the PLC circuit consists of a program interface circuit (PIC) with a microcontroller. It has simultaneous access to the program and data memory technology and integrates a number of the components of a microprocessor system on to a single chip (PIC 16F877). It is built into the CPU, memory, peripherals and other devices, such as timer module, to allow the microcontroller to perform tasks for certain time periods, a serial $\mathrm{I} / \mathrm{O}$ port to allow data to flow between the controller and program interface circuit and an analogue/digital inverter to allow the microcontroller to accept analogue input data for processing.

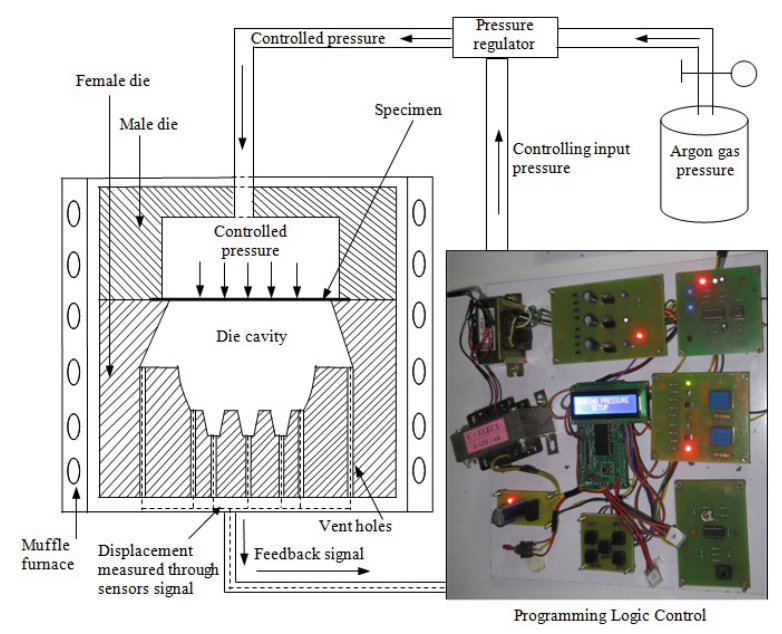

Fig. 2. Experimental setup for PLC control in SPF process

The PLC programme starts to function once the optimum temperature of $450{ }^{\circ} \mathrm{C}$ is reached. The set temperature (optimum experimental temperature) values are received from the temperature control unit, i.e. the PLC programme, starts to open the pressure control valve very slowly and controlling pressure passes on the surface of the blank. Next, the blank starts to be blow formed, the PLC circuit sensors measure the displacement of blank and send feedback to PLC programme. The PLC sensors measure every small positive incremental displacement value at different places of the die surface. The input pressure values are varying with respect to the movement of the blank into the die cavity.

The PLC coding was developed based on the die profile, that is, to release the high quantity of pressure when the blank moves through free regions and reduces the pressure values when the blank move towards die corner and micro forming regions in order to obtain smooth forming profiles. The pressure values are determined by the researcher, based on the die dimensions and fed into the input values through the PLC input key before starting the programme. The input values slowly vary during progress on because of slowly filling of blank in the die corner and micro forming regions thereby eliminating the defects because fast filling may lead to incomplete forming. Similarly, the PLC code was developed based on forming time mode condition.

The experimental process was started with controlling of pressure during forming with two 
different mode conditions. In the first mode condition, pressure was regulated for every incremental displacement $(x)$ of $0.1 \mathrm{~mm}$ during forming of the sheet in the die cavity. Each increment step, the movement was sensed by a sensor and fed back to the program to take appropriate decision. The $x$ value of $0.1 \mathrm{~mm}$ displacement further was reduced to $0.05 \mathrm{~mm}$, if the blank move towards the corner and micro forming regions. The process ran until the blank reached all regions. The displacement values of $0.1 \mathrm{~mm}$ and $0.05 \mathrm{~mm}$ are variable input parameters will modified to appropriate numerical value (with lower value of decimal point) before starting the program.

In the second mode condition, pressure will be regulated for every incremental time of $t$ minute for movement of the blank during the forming of the sheet in to the die cavity. Each time $(t)$ increment steps, the displacement of blank will be sensed by the sensor and feedback will be sent to the program. Further time interval reduced if the blank move towards a corner and micro-forming regions. The time incremental values are variable input parameters and change to any numerical value before starting the program; the appropriate numerical value will be changed when changing the shape of forming. This paper deals with displacement mode condition only.

The die setup consists of male and female dies. The female split die has different dimensions at different stages. The first stage dimensions were kept at a $110^{\circ}$ inside taper angle with a top radius of $30 \mathrm{~mm}$ and a depth of $9 \mathrm{~mm}$. In the second stage, the radius and depth were kept at $30 \mathrm{~mm}$ and $11 \mathrm{~mm}$, respectively. Similarly, for the third stage, tapered grooves with a top radius of $3 \mathrm{~mm}$, bottom radius of $1.5 \mathrm{~mm}$ and a depth of $2.5 \mathrm{~mm}$ were maintained. Finally, the radius at the centre was maintained at $2.5 \mathrm{~mm}$. The die entry radii at the first $\left(\mathrm{R}_{1}\right)$, second $\left(R_{2}\right)$ and third stages $\left(R_{3}\right)$ were kept at $3 \mathrm{~mm}, 2 \mathrm{~mm}$ and $1.5 \mathrm{~mm}$, respectively, as shown in Fig. 3 .

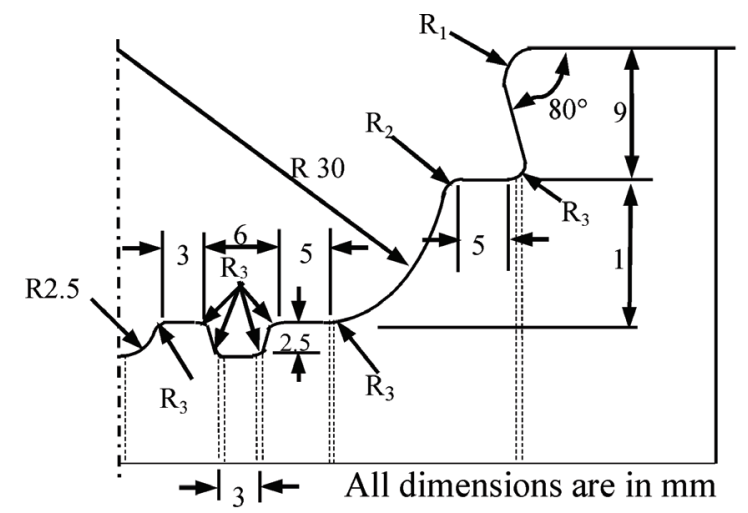

Fig. 3. Illustrations of dimensions in split die
A 72-mm diameter slot was provided in the female die with a depth of $1 \mathrm{~mm}$. The entire die setup, consisting of both the male and female parts, was surrounded without any air gap by a band heater and the entire assembly was placed in a $100 \mathrm{kN}$ hydraulic press under airtight conditions. The die setup was heated up to the optimum temperature [8] of $450{ }^{\circ} \mathrm{C}$ and maintained until the experiment was completed. The 72-mm diameter and $1.5 \mathrm{~mm}$ thick specimens were kept between the male and female parts.

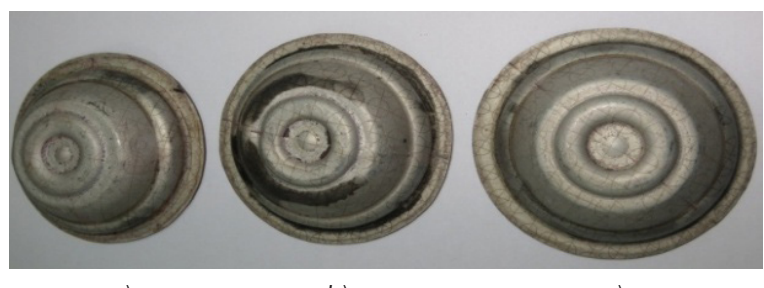

a)

b)

c)

Fig. 4. Experimentally formed components at different pressure control method of:

a) constraint algorithm, b) logarithmic algorithm, and c) PLC

Next, the variable argon gas pressure was applied by three different pressure control method such as logarithmic algorithm [17], constraint algorithm [18] and the newly proposed PLC method. The thickness distribution, forming time and pressure cycle are evaluated for forming components with a function of three different pressure control methods. The final formed components for different pressure control methods are shown in Fig. 4.

\section{FINITE ELEMENT ANALYSIS}

The blank and die configurations employed for FEM in ABAQUS 6.8 of the AA5083 alloy sheet with a multidimensional die profile are shown in Fig. 5. The circular blank with an initial thickness of $1.5 \mathrm{~mm}$ and a diameter of $72 \mathrm{~mm}$ was clamped tightly between the male and female dies using a 6-mm outer rim. Throughout the simulation, the sheet was fixed at the outside edge in order to avoid any possible slipping into the dies. A 3D finite element quarter model was created with the ABAQUS pre-processor and used to study the blow forming process in superplastic forming simulation. The geometry of the blank material was assumed to undergo visco-plastic [8] deformation and the die was assumed to be a discrete rigid body. The blank was meshed with the shell element [14] with 2752 nodes and the rigid die was meshed with R3D3 element with 3018 nodes. In numerical simulation process, the following material data are used. The modulus of elasticity is $75 \mathrm{GPa}$, Poisson's ratio of 0.3 , 
material constant is $159.5 \mathrm{MPas}^{-\mathrm{m}}$, optimum strain rate of $1.21 \times 10^{-3} \mathrm{~s}^{-1}$, strain rate sensitivity index of 0.39 and optimum temperature of $450{ }^{\circ} \mathrm{C}$.

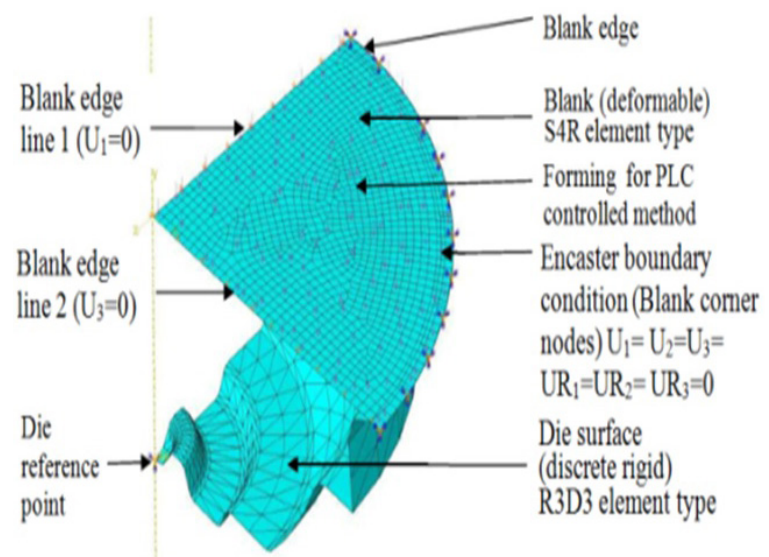

Fig. 5. AA5083 alloy sheet with a multi-dimensional die profile

The gas pressure was imposed on the top surface of the blank was kept at $450^{\circ} \mathrm{C}$. This caused the flow of the sheet into the bottom die cavity gradually. The PLC in FEM simulation was deployed to monitor and control the applied pressure with respect to forming time and displacement in order to maintain the optimum strain rate. Finite element simulations at different stages are shown in Fig. 6. Furthermore, the FEM simulation process was carried out with three different pressure control algorithm approaches.
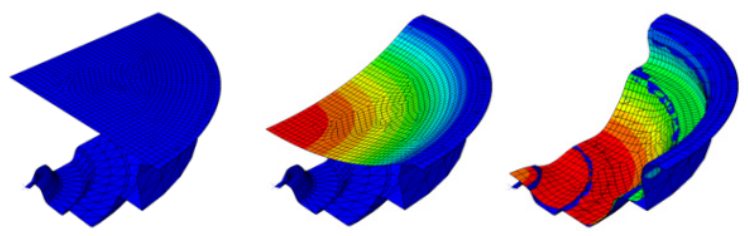

Fig. 6. Finite element simulation process at different stages in PLC method

\section{RESULTS AND DISCUSSIONS}

\subsection{Prediction of Best Pressure Control Method with a Function of Forming Time and Pressure Cycle}

The pressure applied during forming was controlled with accuracy and monitored by a PLC system in all the experiments. The same code has also been generated using the FEM model to predict the forming pressure at target strain rate conditions. The FEM results are compared with experimental values in terms of the pressure-time cycle relationship with target strain rate conditions as shown in Fig. 7. The results show that the FEM results are in good agreement with the experimental values at a maximum error of $2.1 \%$.

Fig. 7 shows the comparison of forming pressure as a function of forming time obtained using the PLC method along with the other two pressure control methods via experiment and FEM at a temperature of $450{ }^{\circ} \mathrm{C}$. The newly developed PLC method and the experimental and FEM simulation results are in close agreement. Comparison of the latter has become imperative with the pressure prediction algorithms such as logarithmic algorithm [17] and constraint algorithm [18]. In a constraint algorithm method, the pressure was controlled by time incremental step from a minimum limit of 0.2 to a maximum level of 3 with different load magnitude, beyond this value the programme was abandoned and restarted according to the following load modifications:

$$
\begin{aligned}
& \text { If } q_{\text {min }}<0.2 \quad \text { then } \quad p_{\text {new }}=2 p_{\text {old }} \\
& \text { If } q_{\text {max }}>3 \text { then } p_{\text {new }}=0.5 p_{\text {old }} \text {, }
\end{aligned}
$$

where $q$ is the ratio of maximum strain rate to target strain rate, $p_{\text {new }}$ is the new pressure magnitude and $p_{\text {old }}$ is the old pressure magnitude from the previous steps. If $0.2<q>3$, the increment is accepted, and the pressure is adjusted as follows.

$$
\begin{aligned}
& \text { If } 0.2<q<0.5 \text { then } p_{\text {new }}=1.5 p_{\text {old }} \\
& \text { If } 0.5<q<0.8 \text { then } p_{\text {new }}=1.2 p_{\text {old }} \\
& \text { If } 0.8 \leq q<1.5 \text { then } \quad p_{\text {new }}=1 p_{\text {old }} \\
& \text { If } 1.5 \leq q<3 \text { then } p_{\text {new }}=0.834 p_{\text {old }} \text {. }
\end{aligned}
$$

The obtained pressure profile at each time increment is applied on the free region of the sheet during forming.

In a logarithmic algorithm method, the time incremental step has been modified in order to obtain the optimum strain rate. The pressure value is obtained for the next time increment by using the following correlation Eq. (1):

$$
P_{n+1}=\left[1-\ln \left(\frac{\dot{\varepsilon}_{\mathrm{max}}}{\dot{\varepsilon}_{\mathrm{opt}}}\right)\right] P,
$$

where $P(t)$ is the forming pressure needed at a time of $t$ until $\dot{\varepsilon}_{\max } / \dot{\varepsilon}_{\text {opt }}>2.72$ This predicts a negative pressure value if the value increases more than 2.72 . In order to prevent this negative pressure, two provisions have been made. First, by choosing small time increment, a rapid change is prevented. Secondly, the applied pressure is reduced by a factor of 0.5 and the analysis is repeated in this manner until this negative pressure is resolved. However, in the PLC method, the pressure was controlled with a function of displacement of the blank in to the die cavity. 
Hojjati et al. [17] have analysed the optimum pressure profile and thickness distribution using three different pressure levels (0.6 MPa, 0.8 MPa and $1 \mathrm{MPa}$ ) as well as constraint and logarithmic algorithms. They report that the logarithmic algorithm method gives better results for achieving uniform thickness distribution with minimum forming time. On comparing the results based on the existing algorithms with the results obtained using PLC, it can be clearly seen that the PLC process gives better results in a multi-dimensional profile, as evident in Fig. 7 and Table 2. Fig. 7 shows that the applied pressure gradually keeps increasing until the blank reaches the die surface beyond which it gradually decreases to achieve uniform thickness distribution in a multi-dome shape in all the three control processes.

Table 2. Forming time obtained with different pressure control processes

\begin{tabular}{|c|c|c|c|c|c|c|}
\hline \multirow{2}{*}{$\begin{array}{l}\text { Pressure } \\
\text { forming } \\
\text { method }\end{array}$} & \multicolumn{2}{|c|}{ Time [min] } & \multirow{2}{*}{$\begin{array}{l}\% \text { of } \\
\text { error }\end{array}$} & \multicolumn{2}{|c|}{$\begin{array}{l}\text { Forming pressure [MPa] } \\
\text { at maximum level }\end{array}$} & \multirow{2}{*}{$\begin{array}{l}\% \text { of } \\
\text { error }\end{array}$} \\
\hline & Exp & FEA & & Exp & FEA & \\
\hline $\begin{array}{l}\text { Constraint } \\
\text { algorithm }\end{array}$ & 62 & 63.56 & 2.52 & 0.43 & 0.445 & 3.5 \\
\hline $\begin{array}{l}\text { Logarithmic } \\
\text { algorithm }\end{array}$ & 57 & 58.14 & 2.0 & 0.45 & 0.462 & 2.7 \\
\hline $\begin{array}{l}\text { PLC } \\
\text { approach }\end{array}$ & 51 & 52.12 & 2.2 & 0.39 & 0.398 & 2.1 \\
\hline
\end{tabular}

In the constraint algorithm method, the applied pressure has a step-by-step magnitude increment process reflecting higher oscillations in the stress and therefore results in a variation in pressure profile in the die entry and corner regions with high pressure of $0.43 \mathrm{MPa}$ and a forming duration of 62 minutes. The logarithmic algorithm method requires a higher pressure of $0.45 \mathrm{MPa}$ with forming duration of 57 minutes to complete the profile with more oscillations in the stress. It reflects the variation in pressure profile in corner regions.

In the PLC approach, $0.39 \mathrm{MPa}$ of maximum pressure level is needed to fill the die cavity within 51 minutes and the smooth pressure profile has been achieved, as evident in Fig. 7. In the PLC method, the forming time decreases because of greatly reduced oscillations and stress during forming at corners regions. Fig. 7 and Table 2, shows that the optimum (minimum) forming pressure $0.39 \mathrm{MPa}$, forming time of 51 minutes, and smooth pressure cycle have been obtained in the PLC method, compared to other pressure control methods. This is because the entire PLC pressure cycle method has been developed based on the forming height with respect to strain rate and a temperature. Furthermore, the PLC-based pressure cycle mechatronics approach will be designed and constructed to change the amplitude (very small) of displacement step during forming. This approach can also be more flexible and highly precise to regulate the flow of pressure for slow filling in corner regions, thereby eliminating oscillations and premature fracture.

\subsection{Prediction of Best Pressure Control Method with a Function of Thinning Factor for Optimizing Thickness Distribution}

The superplastic forming processes were carried out experimentally and numerically using constraint algorithm, logarithmic algorithm and PLC approach in a multistage multidimensional split die model, the and results of thickness distribution are shown in Fig. 8.

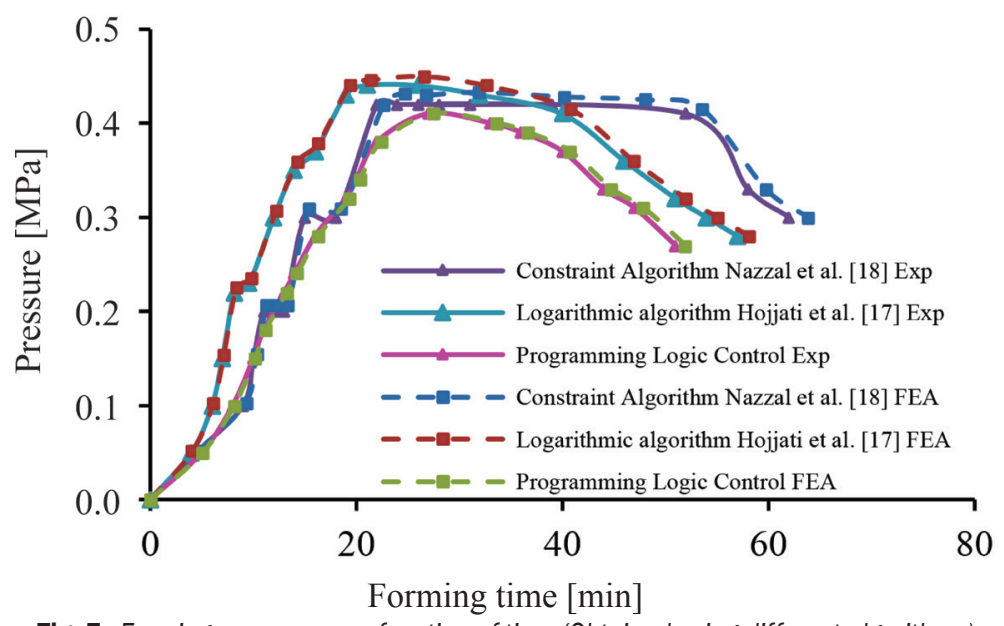

Fig. 7. Forming pressure as a function of time (Obtained using different algorithms) 
The thickness distribution is shown as a function of distance from the centre of the split die in all these three different pressure control methods. The thinning factors [17] for all pressure control methods are shown in Table 3. The thinning factor values obtained from finite element model have been found to be very close to those obtained from actual experiments with a maximum error of $3 \%$ in constraint algorithm method. The thinning factor with a function of different pressure control method by the FEA and the values obtained through the experiments are found to agree very well with a minimum percentage error as shown in Table 3.

Table 3. Thinning factor in different pressure control method

\begin{tabular}{clccc}
\hline \multirow{2}{*}{$\begin{array}{c}\text { S. } \\
\text { no }\end{array}$} & Pressure forming method & \multicolumn{2}{c}{ Thinning factor [\%] } & \multirow{2}{*}{$\begin{array}{c}\text { \% of } \\
\text { error }\end{array}$} \\
\cline { 3 - 4 } & & Experiment & FEA & \\
\hline 1 & Constraint algorithm & 78.26 & 80.61 & 3.00 \\
\hline 2 & Logarithmic algorithm & 80.40 & 82.41 & 2.50 \\
\hline 3 & PLC approach & 88.41 & 89.96 & 1.75 \\
\hline
\end{tabular}

The thinning factor [17] plays a vital role in predicting the uniformity of thickness in the formed profile with the highest value indicating more uniform thickness distribution in the product. Table 3 shows that the PLC approach has a higher thinning factor
$(88.41 \%)$ value in comparison to the logarithmic algorithm (thinning factor $80.4 \%$ ) and the constraint algorithm (thinning factor $78.26 \%$ ). Furthermore, Fig. 8 shows that the PLC process has obtained optimum (minimum) thickness variation when compared to the constraint and logarithmic algorithm approaches. Therefore, the experimental results, helps understanding that; in this case, the uniform thickness has been achieved using the newly developed pressure control method of PLC approach.

In the fully formed component, more thickness variations were observed at the die entry, taper angle, die corner, hemispherical and micro-forming regions with the constraint algorithm method due to the maximum pressure magnitude interval step followed in this algorithm. Similarly, the use of the logarithmic algorithm method is also not so uniform in all the regions of the die due to the time step interval. However, in the PLC process, thickness distribution can be found to be very close to uniform (optimum thickness variation) in all the regions of the die, as evident from Fig. 8. The reasons for the even thickness distribution in this case could be the very small, and gradual increments possible either in displacement or in time, thereby reducing flow stress oscillations significantly, even in die corner regions.

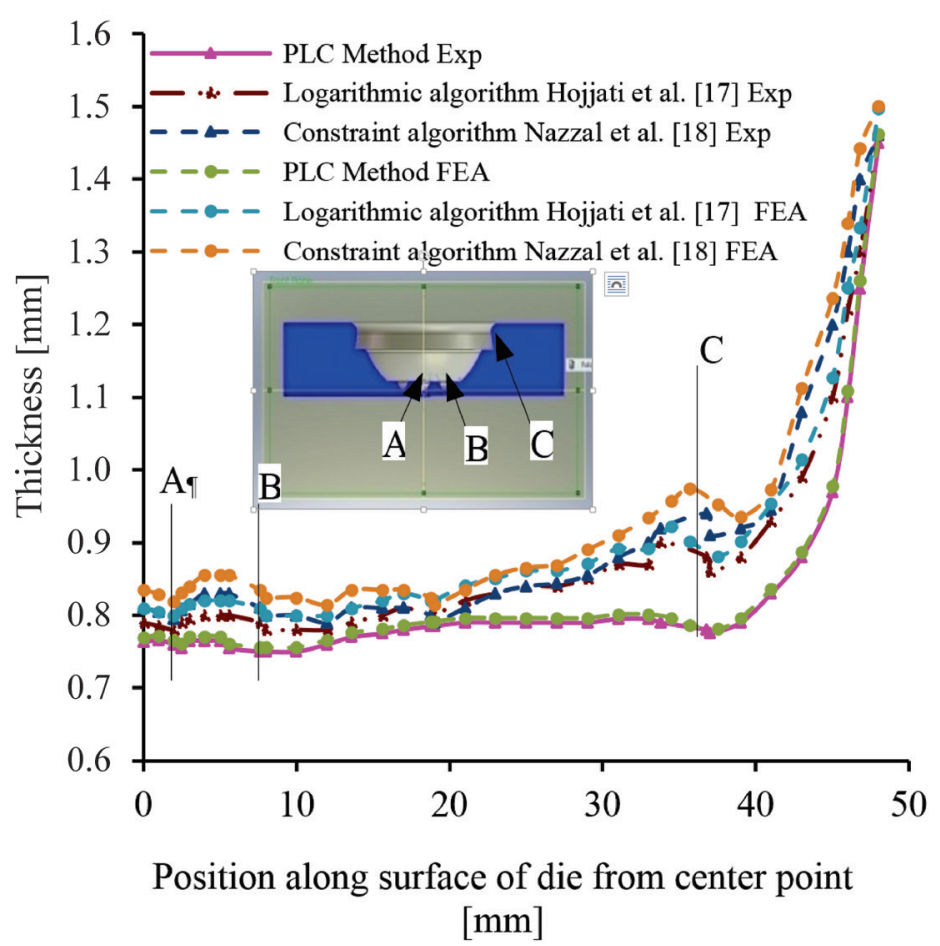

Fig. 8. Thickness distribution along the die surface with different pressure control algorithm 
This approach can also be more flexible and highly precise to regulate the flow of pressure for slow filling in corner regions, thereby eliminating the defects because of otherwise fast filling. For this reason, the PLC approach has the best pressure prediction method to control the flow and strain rate throughout the process and obtained optimum thickness variation (uniform thickness distribution) in multiple curved regions.

\subsection{Effect of Strain Rate Sensitivity Index on Thickness Distribution and Pressure Time Cycle}

The strain rate sensitivity index $(m)$ plays an important role in the SPF process, since it affects the forming pressure and strain rate. The influence of $m$ values on the pressure-time cycle profile and thickness distribution is shown in Figs. 9 and 10. Fig. 9 clearly shows that a low value of strain rate sensitivity index ( $m=0.3$ ) leads to a dramatic increase in the forming pressure $(1.43 \mathrm{MPa})$ required to fill the die cavity uniformly in a multi-dome profile. In contrast, an increase in the $m(0.5)$ value increases the forming time (104 minutes) required to complete filling the cavity of the multidimensional profile, despite reports [4] and [20] which suggest that higher ' $m$ ' values produce a homogeneous thickness distribution in simple-shaped components. In the present PLC process, a significant variation in thickness is found during very low and very high ' $m$ ' values which can be seen in Fig. 10.

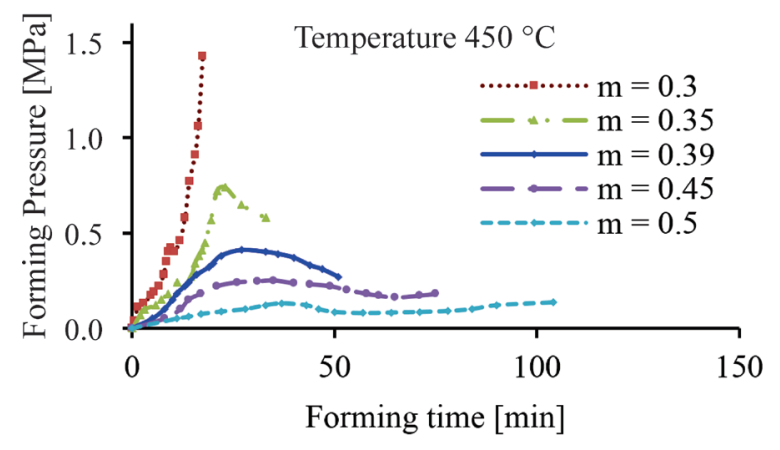

Fig. 9. Influence of the $m$ value on the pressure time cycle

Figs. 9 and 10 show that at an optimum 'm' value of 0.39 filling the die cavity has been achieved with nominal (maximum) forming of pressure is $0.398 \mathrm{MPa}$ and at a relatively short time of 52.12 minutes, which has also produced uniform thickness distribution in the complex profile. Moreover, with the optimum ' $m$ ' (0.39) value, the variation in the thickness profile in the die corner and entry regions is insignificant, as the optimal value results in greater resistance to neck formation and, therefore, good material flow [21] in the multiple curved die entry regions is ensured.

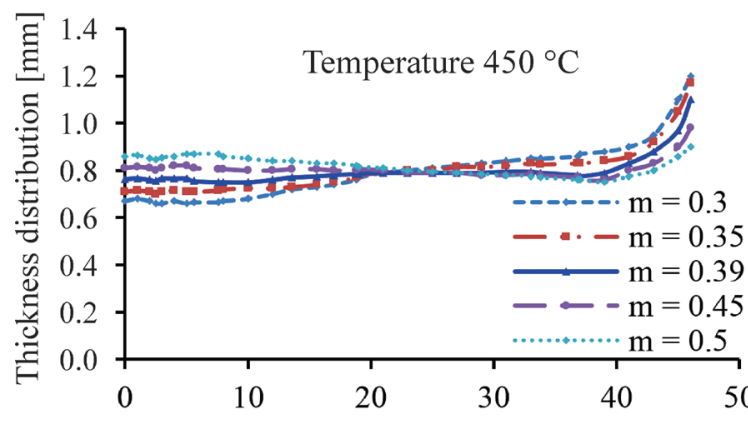

Distance from center of the die [mm]

Fig. 10. Influence of the $m$ value on the thickness distribution

\subsection{Effect of Friction Coefficient on Thickness Profile}

The coefficient of friction is an important factor that influences the forming pressure during superplastic forming. Most of the published works have focused on simple shapes, such as hemispherical, circular, cone, and also with a relatively simple rectangular die. In this work, the effect of the coefficient of friction on thickness variations in different die entry and die corner regions has been simulated using Coulomb's friction model [17] method in FEA and a complex with multi-dimensional profile. The SPF process is numerically simulated with coefficient of friction values of $0.0,0.2$, and 0.4 [16] and [17] and their effects on important parameters, such as thickness variations are studied and the results are reported in Fig. 11.

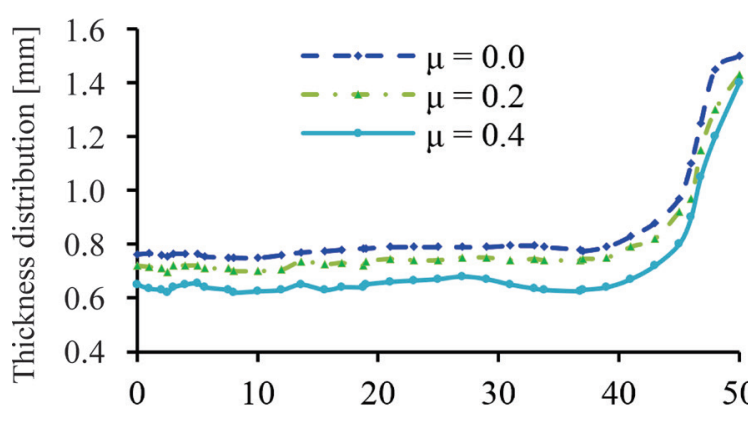

Distance from center of the die [mm]

Fig. 11. Thickness distribution along the die surface with different coefficient of friction using PLC method

When the material starts flowing, the initial contact between the die and the blank takes place at the die entry point. Due to sliding under pressure, 
the thickness of the profile varies as a function of the friction coefficient. The deviation in thickness distribution is high in the forming profile when the coefficient of friction is high. Fig. 11 shows that lower coefficient of friction results in uniform thinning at the die entry and the die corner regions. Higher coefficient of friction results in non-uniform thinning which in turn leads to higher deviation in thickness values in the die entry and corner regions. A higher value of friction coefficient also results in localized thinning in the profile in regions other than die entry regions of the dome. Lower values of friction coefficient lead to smooth material flow into the die cavity, obtained by controlling of applied pressure within the PLC, and result in uniform thickness distribution in die entry and corner regions of the profile. Therefore, using the PLC method, uniform thickness distribution has been predicted even for a multidimensional profile by keeping the coefficient of friction at a lower value, which further validates the utility of the approach.

\subsection{Microstructure in Parent Metal of AA 5083 Aluminium Alloy}

The optical microstructure analysis has been carried out in the parent metal at room temperature. The optical microstructures of the initial as-received material are shown in Fig. 12, which reveals coarse equiaxed grains.

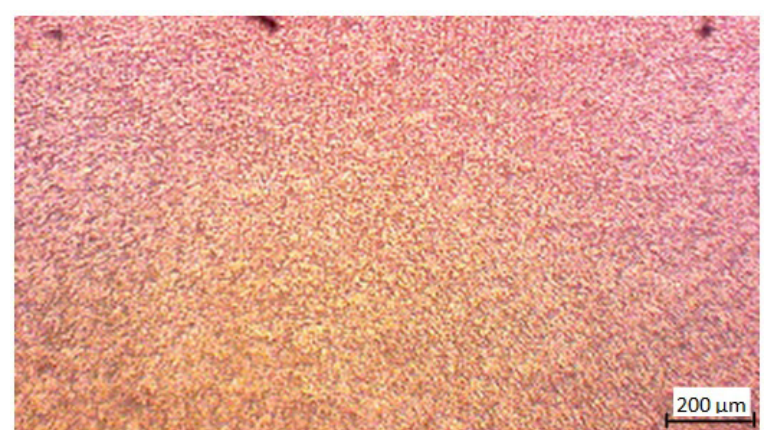

Fig. 12. Microstructure of parent metal

\subsection{Microstructure Analysis in Three-Stage Multi- dimensional Formed Component}

The microstructure analysis has been carried out at four locations: taper angle corner point, die corner points and midpoint of micro-forming region of three stage multidimensional formed components obtained by using the PLC method at a temperature of $450{ }^{\circ} \mathrm{C}$. The microstructure locations are shown in Fig. 13.
From Fig. 13, it is seen that the matrix shows elongated grains of $\mathrm{Mg}_{2} \mathrm{Si}$ particles/grains in aluminium solid solution. The finest grain size could be seen in optical microstructures of superplastic formed components. Further microstructures in all the locations are identical and no stress affected microstructure could be seen. With the PLC method, the material flow at a very slow rate to fill the die corner regions, so there is no significant change in microstructure of the formed component.

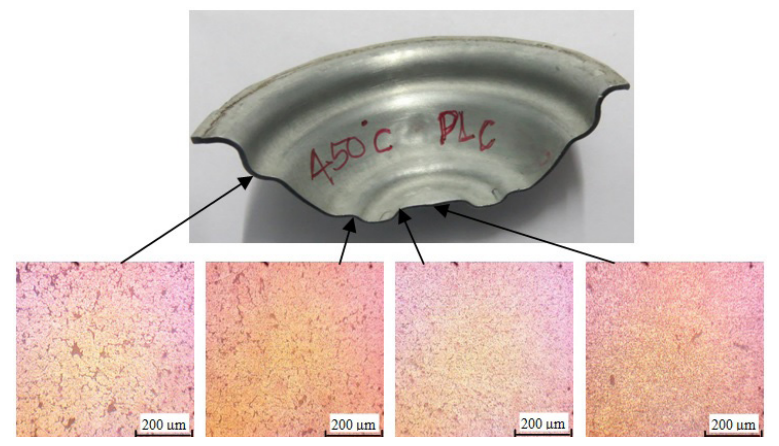

Fig. 13. Microstructure at various points on formed profile by using PLC approach

\section{CONCLUSION}

The PLC approach has been employed in the superplastic forming process of AA 5083 alloy in order to predict the optimum pressure required to improve the uniform thickness profile in multigeometrical components. The pressure-time cycle, obtained based on this approach, has shown uniform thickness distribution in the multidimensional profile with minimum forming time when compared to the results obtained using constrained and logarithmic control algorithms. The finite element method has been used to ensure accurate control of the pressure into a multi-stage profile to improve the thickness profile without wrinkles. The pressure profile predicted by the FEM (ABAQUS) compared very well with the experimental results.

The developed PLC system is found to effectively control superplastic forming of the AA5083 alloy sheet into the cavity without any significant necking. Thickness distribution in the die entry and corner regions has been found to be uniform for a complex multidimensional profile, such as the one used in this work. The PLC circuit has also been found to be effective in adjusting the magnitude and duration of the pressure cycle, to optimize thickness quality, and to achieve wrinkle-free superplastic formed multidimensional components. The results reveal 
FEM to be a very reliable method for analysing and optimizing the superplastic forming process by varying friction levels and strain rate sensitivity index both of which help to predict important parameters, such as thickness distribution, forming time, and pressure profile.

\section{REFERENCES}

[1] Ghosh, A.K., Hamilton, C.H. (1980). Superplastic forming of a long rectangular box section-analysis and experiment, processing modeling, fundamentals and application of metals. Proceeding of American Society of Metals, Materials and Process, p. 303-331.

[2] Rama, SC., Chandra, N. (1991). Development of a pressure prediction method for superplastic forming processes. International Journal of Non-Linear Mechanics, vol. 26, no. 5, p. 711-725, DOl:10.1016/0020-7462(91)90022-L.

[3] Luckey, S.G., Friedman, P.A., Xia, Z.C. (2004). Aspects of element formulation and strain rate control in the numerical modeling of superplastic forming. Proceedings of advances in superplasticity and superplastic forming. The Minerals, Metals and Materials Society, p. 371-380.

[4] Chen, Y., Kibble, K., Hall, R., Huang, X. (2001). Numerical analysis of superplastic blow forming of Ti-6Al-4V alloys. Materials and Design, vol. 22, no. 8, p. 679-685, Dol:10.1016/ S0261-3069(01) 00009-7.

[5] Gusel, L., Rudolf, R., Brezocnik, M. (2015). Genetic based approach to predicting the elongation of drawn alloy. International Journal of Simulation Modelling, vol. 14, no. 1, p. 39-47, DOI:10.2507/IJSIMM14(1)4.277.

[6] Dutta, A., Mukherjee, AK. (1992). Superplastic forming: an analytical approach. Journal of Material Science and Engineering: A, vol. 157, no. 1, p. 9-13, Dol:10.1016/09215093(92)90092-F.

[7] Jarrar, F.S., Abu-Farha, F.K., Hector, L.G.Jr., Khraisheh, M.K.(2009). Simulation of high-temperature AA5083 bulge forming with hardening/softening material model. Journal of Material Engineering Performance, vol. 18, p. 863-870, DOI:10.1007/S11665-008-9322-5.

[8] Balasubramanian, M., Ganesh, P., Ramanathan, K., Senthil Kumar, V.S. (2015).Superplastic forming of a three-stage hemispherical 5083 Aluminium profile. Strojniški vestnik Journal of Mechanical Engineering, vol. 61, no. 6, p. 365-373, DOI:10.5545/sv-jme.2014.2178.

[9] Carrino, L., Giuliano, G.,Napolitana, G. (2003). A posteriori optimisation of the forming pressure in superplastic forming processes by the finite element method. Finite Element in Analysis and Design, vol. 39, no. 11, p. 1083-1093, Dol:10.1016/S0168-874X(02)00158-0.

[10] Snippe, Q.H.C., Meinders, T. (2011). Mechanical experiments on the superplastic material ALNOVI-1, including leak information. Journal of Material Science and Engineering: A, vol. 528, no. 3, p. 950-960, Dol:10.1016/j.msea.2010.09.075.

[11] Dezelak, M., Stepisnik, A., Pahole, I., Ficko, M. (2014). Evaluation of twist springback prediction after an AHSS forming process. International Journal of Simulation Modelling, vol. 13, no. 2, p. 171-182, Dol:10.2507/IJSIMM13(2)4.261.

[12] Hambli, R., Potiron, A., Guerin, F., Dumon, B. (2001). Numerical pressure prediction algorithm of superplastic forming processing using $2 \mathrm{D}$ and $3 \mathrm{D}$ models. Journal of Materials Processing Technology, vol. 112, no. 1, p. 83-90, DOI:10.1016/S0924-0136(01)00549-0.

[13] Nițu, E., Iordache, M., Marincei, L., Charpentier, I., Le Coz, G., Ferron, G., Ungureanu, I. (2011). FE-modeling of cold rolling by in-feed method of circular grooves. Strojniški vestnik -Journal of Mechanical Engineering, vol. 57, no. 9, p. 667-673, D0l:10.5545/sv-jme.2010.244.

[14] Luckey, S.G.Jr., Friedman, P.A., Weinmann, K.J. (2007). Correlation of finite element analysis to superplastic forming experiments. Journal of Materials Processing Technology, vol. 194, no. 1-3, p. 30-37, D0l:10.1016/j.jmatprotec.2007.03.122.

[15] Aoura, Y., Boude, S., Santo, PD., Ouziz, L. (2011). Experimental validation of pressure cycle for superplastic forming of Ti-6Al$4 \mathrm{~V}$ alloys. International Journal of Research and Review in Mechatronics Design and Simulation, vol. 1, no. 2, p. 32-36.

[16] Jarrar, F.S., Hector, L.G.Jr., Khraisheh, M.K., Bower, A.F. (2010). New approach to gas pressure profile prediction for high temperature AA5083 sheet forming. Journal of Materials Processing Technology, vol. 210, no. 6-7, p. 825-834, DOl:10.1016/J.jmatprotec.2010.01.002.

[17] Hojjati, M.H., Zoorabadi, M., Hosseinipour, S.J. (2008). Optimization of superplastic hydroforming process of Aluminium alloy 5083. Journal of Materials Processing Technology, vol. 205, no. 1-3, p. 482-488, D0l:10.1016/j. jmatprotec.2007.11.208.

[18] Nazzal, M.A., Khraisheh, M.K., Darras, B.M. (2004). Finite element modeling and optimization of superplastic forming using variable strain rate approach. Journal of Materials Engineering and Performance, vol. 13, no. 6, p. 691-699, DOI:10.1361/10599490421321.

[19] SenthilKumar, V.S., Viswanathan, D., Natarajan, S.(2006). Theoretical prediction and FEM analysis of superplastic forming of AA7475 aluminum alloy in a hemispherical die. Journal of Materials Processing Technology, vol. 173, no.3, p. 247251, D0I:10.1016/J.jmatprotec.2005.04.112.

[20] Li, G.Y., Tan, M.J.,Liew, K.M. (2004). Three-dimensional modeling and simulation of superplastic forming. Journal of Materials Processing Technology, vol. 150, no. 1-2, p. 76-83, DOI:10.1016/J.jmatprotec.2004.01.023.

[21] Cornfield, G.C., Johnson, R.H. (1970). The forming of superplastic sheet metal. International Journal of Mechanical Science, vol. 12, no. 6, p.479-490, Dol:10.1016/00207403(70)90075-5. 